\title{
Inguinal Hernia with Incarcerated loop of Sigmoid Colon and Impacted Hard Fecolith in an Infant: Rare Presentation
}

\author{
Nitin jain ${ }^{1}$, Parveen Kumar ${ }^{2 *}$ \\ ${ }^{1}$ Pediatric Surgery, MAMC, New Delhi. \\ ${ }^{2}$ Pediatric Surgery, CNBC, New Delhi.
}

*Corresponding Author: Parveen Kumar, Pediatric Surgery, CNBC, New Delhi.

Received Date: 10 July 2021 | Accepted Date: 09 September 2021 | Published Date: 17 September 2021

Citation: P Kumar. (2021). Inguinal Hernia with Incarcerated loop of Sigmoid Colon and Impacted Hard Fecolith in an Infant: Rare Presentation. International Journal of Clinical Case Reports and Reviews. 8(4); DOI:10.31579/2690-4861/155

Copyright: () 2021 Parveen Kumar, This is an open-access article distributed under the terms of the Creative Commons Attribution License, which permits unrestricted use, distribution, and reproduction in any medium, provided the original author and source are credited.

Abstract
Incarcerated inguinal hernia is not an uncommon occurrence and the rate of incarceration in inguinal hernias has
been variably reported between 3 and $16 \%$ with higher incidence among infants. Sigmoid colon as a content of hernia
is itself an uncommon occurrence and associated impacted large and hard fecolith makes it a rare case in pediatric
age group. Only single published case report could be found depicting these findings in young age group. Here we
report 1-year-old child presented with 24 hours history of obstructed left-sided inguinal hernia. On exploration loop
of sigmoid colon was identified with impacted fecolith.
Keywords: hernia; sigmoid colon; fecolith; inguinal hernia; incarceration

\section{Introduction}

Inguinal hernia is one of the most common surgical conditions with an overall incidence of $0.8 \%$ to $5 \%$ in full-term infants $[1,2]$. but the risk is significantly increased (upto $30 \%)$ in low birth weight $(<1 \mathrm{~kg})$ and premature infants $[2,3]$. The risk of incarceration in children ranges from $3 \%$ to $16 \%$, although it is as high as $31 \%$ in premature infants, with most occurring within the first year of life $[4,5]$. Most of the cases present with a swelling in groin area that increases on straining, discovered by the parents or a pediatrician. Complications may present as incarceration of the herniating abdominal contents, with or without features of intestinal obstruction. Strangulation occurs if not attended early and poses a risk of increased morbidity and mortality. The incidence of incarceration is higher in first 1 or 2 years of life as they have a smaller and tighter internal ring and inguinal canal that easily traps the herniating loops of bowel. Obstructed inguinal hernia with incarcerated bowel loops and impacted fecolith is even uncommon especially in infants and younger age group. Here we report and discuss a case of incarcerated inguinal hernia with impacted hard fecolith who presented after 24 hours of irreducibility but before signs of strangulation. Inguinal exploration revealed obstructed bowel loop with hard fecolith, which was removed via enterotomy and bowel repaired, reduced and repositioned.

\section{Case Report}

A 1-year-old child presented to the emergency department with painful left-sided inguinal swelling for 24 hours. Child also had history of two episodes of non-bilious vomiting and mild abdominal distension.
According to the mother swelling was initially reducible, that used to increase on crying and decreased on sleeping for the last 2 months. But over the last 24 hours, mother noticed that the swelling wasn't reducing and was then followed by 2 episodes of non-bilious vomiting, reluctance to feeds, mild abdominal distension, excessive crying and irritability. Mother also gave history of constipation and passing hard stools over the last two months. On asking about dietary history, mother revealed that the child was consuming milk as staple diet. At presentation child was conscious, and alert with no signs of respiratory distress. His vitals were blood pressure of $88 / 50 \mathrm{mmHg}$, heart rate 119 beats/min, respiratory rate 18 breaths/min and temperature was $99.2^{\circ} \mathrm{F}$. Oxygen $(\mathrm{O} 2)$ saturation was $97 \%$ on room air. Pertinent physical findings revealed globular, tender and irreducible swelling in left inguinal region with no visible signs of inflammation. Left sided testis could be palpated at the root of scrotum. Abdomen was soft with mild fullness but without any signs of peritoneal irritation. Rectal examination was not done. Emergency ultrasound abdomen was done that suggested left sided inguinal hernia with bowel loops as contents. Bowel wall showed vascularity and mild fluid in hernial sac. Haematological investigations revealed hemoglobin $11.3 \mathrm{~g} / \mathrm{dl}$, TLC 12,600/dl, Platelet count 2.8L/mm3, HCT 39\%, T. Bilirubin $0.3 \mathrm{mg} / \mathrm{dl}$, AST/ALT 46/53 U/L, blood urea $11 \mathrm{mg} / \mathrm{dl}$, serum creatinine $0.9 \mathrm{mg} / \mathrm{dl}, \mathrm{Na}^{+} 138 \mathrm{meq} / \mathrm{L}, \mathrm{K}^{+} 3.6 \mathrm{meq} / \mathrm{L}$ and normal coagulation profile (PT 12s, INR 1.1). Patient was planned for emergency operation and leftsided inguinal exploration was done. Intra-operatively hernial sac was identified with dilated healthy segment of sigmoid colon obstructed at the neck of sac with hard fecolith (Fig.1). Colour and peristaltic activity of bowel segment was normal. As fecolith impacted loop could not be 
reduced, enterotomy was done and fecolith was removed (Fig.2). After the closure of enterotomy and wound lavage, deep inguinal ring was dilated and bowel segment was reduced. Herniotomy was done with posterior wall strengthening and wound was closed in layers. Intraoperatively per rectal examination was done and impacted hard stool pellets were removed. Postoperative period was uneventful and child passed stools on third postoperative day. The child was started oral feeds on the fourth postoperative day and discharged next day. Mother was given a dietary plan for child regarding decrease milk intake and starting complementary feeds with increased fibre and solid diet. Child followed up in outpatient after 1 week. He was asymptomatic and tolerated feeds without bloating, distension or emesis.

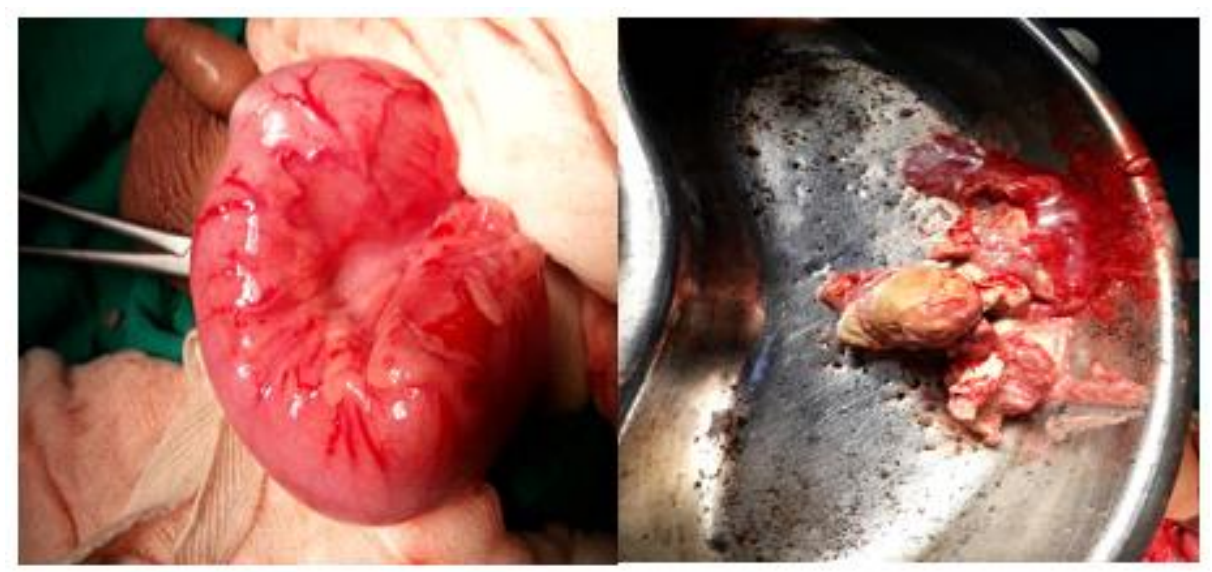

Figure 1 and 2: Intra-operative pictures showing loop of sigmoid colon with impacted fecolith and removed hard fecoliths after enterotomy.

\section{Discussion}

The rate of incarceration in inguinal hernias has been reported between 3 to $16 \%$ with higher incidence among infants. [5] This can be explained because of smaller inguinal canal and internal ring through which loops of herniating bowel can easily be trapped causing obstruction or later strangulation. Most inguinal hernias are reducible at presentation but become complicated when incarceration occurs and this may progress to intestinal obstruction. Initially the contents usually loops of bowel are trapped at the neck of the sac which is already small and narrow without interference to the blood supply. Because of the obstruction, venous congestion and oedema of the wall occurs, progressing if not reduced to bowel ischemia, infarction and gangrene termed strangulation. [6] An incarcerated hernia presents as an irreducible inguinal bulge that is tender and may be erythematous. The child is usually irritable, and may have obstructive symptoms such as nausea/vomiting, not passing stools, and abdominal distention. If incarceration progresses to strangulation, the child may have peritonitis, bloody stools, and hemodynamic instability. Other conditions may be confused for an incarcerated hernia, such as a retractile testis, lymphadenopathy, and hydrocele. [7] Although ultrasonography has been described as a tool to help differentiate these causes, [8] physical examination can help make the correct diagnosis. Obstructed inguinal hernia with incarcerated bowel loops and impacted fecoliths is an uncommon event in younger age group. Only single published case report was found depicting findings of obstructed inguinal hernia with incarcerated bowel loops and impacted hard fecoliths in young pediatric age group. [9]

\section{Conclusion}

Our goal of this case publication is to show that sigmoid colon with impacted hard fecoliths can be a content of incarcerated inguinal hernia even though it is an extremely rare presentation. Timely investigation and treatment helps in preventing possible morbidity or mortality secondary to complications.

\section{References}

1. Chang SJ, Chen JC, Hsu CK, Chuang FC, Yang SD. (2016). The incidence of inguinal hernia and associated risk factors of incarceration in pediatric inguinal hernia: a nationwide longitudinal population-based study. Hernia. 20(4):559-563.

2. Burgmeier C, Dreyhaupt J, Schier F. (2014). Comparison of inguinal hernia and asymptomatic patent processus vaginalis in term and preterm infants. J Pediatr Surg. 49(9):1416-1418.

3. Lautz TB, Raval MV, Reynolds M. (2011). Does timing matter? A national perspective on the risk of incarceration in premature neonates with inguinal hernia. J Pediatr. 158(4): 573-577.

4. Stylianos S, Jacir NN, Harris BH. (1993). Incarceration of inguinal hernia in infants prior to elective repair. J Pediatr Surg. 28(4):582583.

5. Rajput A, Gauderer MWL, Hack M. (1992). Inguinal hernias in very low birth weight infants: incidence and timing of repair. J Pediatr Surg. 27(10):1322-1324.

6. Parmar G, Dabhoiwala T, Hathila VP. (2008). Uncommon presentation of inguinal hernia: Burst obstructed inguinal hernia with ileo-ileal intussusception. Internet J Surg.

7. Fraser JD, Snyder CL. (2014). Inguinal hernias and hydroceles. In: Ashcraft KW, Holcomb GW, Murphy JP, et al, editors. Ashcraft's pediatric surgery. 6th edition. London: Saunders/Elsevier. 679-686.

8. Mishra DS, Magu S, Sharma N, Rattan KN, Tewari AD, Rohilla S. (2003). Imaging in acute abdomen. Indian J Pediatr. 70(1):15-19.

9. Roy AK, Ghildiyal JP. (2008). Impaction of feces in a loop of sigmoid colon: A rare cause of incarceration of inguinal hernia in children. Internat J surg. 6(6):7-8. 
(c) ()

This work is licensed under Creative

Commons Attribution 4.0 License

To Submit Your Article Click Here: Submit Manuscript

DOI: $10.31579 / 2690-4861 / 155$
Ready to submit your research? Choose Auctores and benefit from:

$>$ fast, convenient online submission

$>$ rigorous peer review by experienced research in your field

$>$ rapid publication on acceptance

$>$ authors retain copyrights

$>$ unique DOI for all articles

$>$ immediate, unrestricted online access

At Auctores, research is always in progress.

Learn more https://auctoresonline.org/journals/international-journal-ofclinical-case-reports-and-reviews 